Hydrol. Earth Syst. Sci. Discuss., doi:10.5194/hess-2016-566, 2017

\title{
Uncertainty analysis of hydrological return period estimation, taking the upper Yangtze River as an example
}

\author{
Hemin Sun ${ }^{1,2}$, Tong Jiang ${ }^{1,2}$, Cheng Jing ${ }^{1,2}$, Buda $\mathrm{Su}^{1,2,3}$, and Guojie Wang ${ }^{1}$ \\ ${ }^{1}$ Collaborative Innovation Center on Forecast and Evaluation of Meteorological Disasters, Nanjing University of \\ 5 Information Science \& Technology, Nanjing, 210044, China \\ ${ }^{2}$ National Climate Center, China Meteorological Administration, Beijing, 100081, China \\ ${ }^{3}$ State Key Laboratory of Desert and Oasis Ecology, Xinjiang Institute of Ecology and Geography, Chinese Academy of \\ Sciences, Urumqi, 830011, China
}

Correspondence to: Buda Su (subd@cma.gov.cn) and Guojie Wang (gwang_nuist@163.com)

10 Abstract. Return period estimation plays an important role in the engineering practices of water resources and disaster management, but uncertainties accompany the calculation process. Based on the daily discharge records at two gauging stations (Cuntan and Pingshan) on the upper Yangtze River, three sampling methods (SMs; (annual maximum, peak over threshold, and decadal peak over threshold), five distribution functions (DFs; gamma, Gumbel, lognormal, Pearson III, and general extreme value), and three parameterization methods (PMs; maximum likelihood, L-Moment, and method of moment)

15 were applied to analyze the uncertainties in return period estimation. The estimated return levels based on the different approaches were found to differ considerably at each station. The range of discharge for a 20 -year return period was 63,800.8-74,024.1 m3 s-1 for Cuntan and 23,097.8-25,595.3 m3 s-1 for Pingshan, when using the 45 combinations of SMs, DFs, and PMs. For a 1000-year event, the estimated discharge ranges increased to 74,492.5-125,658.0 and 27,339.241,718.1 m3 s-1 for Cuntan and Pingshan, respectively. Application of the analysis of variance method showed that the total sum of the squares of the estimated return levels increased with the widening of the return periods, suggestive of increased uncertainties. However, the contributions of the different sources to the uncertainties were different. For Cuntan, where the discharge changed significantly, the SM appeared to be the largest source of uncertainty. For Pingshan, where the discharge series remained almost stable, the DF contributed most to the uncertainty. Therefore, multiple uncertainty sources in estimating return periods should be considered to meet the demands of different planning purposes. The research results also suggest that uncertainties of return level estimation could be reduced if an optimized DF were used, or if the decadal peak over threshold SM were used, which is capable of representing temporal changes of hydrological series.

\section{Introduction}

A warming climate will cause increasingly frequent and more severe extreme events, exposing human society and ecosystems to greater climatic extremes (IPCC, 2014, Qin et al., 2015). Flooding and drought are among those extreme events that often cause huge damage. To cope with hydrological extremes, appropriate assessment of disaster and the 
Hydrol. Earth Syst. Sci. Discuss., doi:10.5194/hess-2016-566, 2017

Manuscript under review for journal Hydrol. Earth Syst. Sci.

Published: 7 February 2017

construction of hydraulic projects such as dams, bridges, and pipelines are greatly needed (Rosbjerg and Madsen, 1998; Milly et al., 2002; Cooley et al., 2007; Salvadori et al., 2011; Rootzén and Katz, 2013). Disaster assessment and mitigation relies heavily on the return period of hydrological extremes, where a $T$-year return period represents an event that has a $1 / \mathrm{T}$ chance of occurrence in any given year. However, because of limitations in understanding and data limitation, substantial

5 uncertainties accompany the fitting of extreme hydrological events, and it is necessary to quantify the uncertainties for robust decision making (Kay et al., 2006; Salvadori et al., 2011). Typically, an estimation of return period uses an appropriate parameterization method (PMs) to fit a candidate distribution for an extreme series. Uncertainty might stem from any procedure used in establishing the extreme series from the available data, selecting the distribution functions (DFs), or performing the parameterization process (Beck, 1987; Hoffman and Hammonds, 1994; El Adlouni, 2008; AghaKouchak and

10 Nasrollahi, 2010).

Since Horton (1896) used a normal distribution to fit hydrological extremes, many distribution families have been built. Their suitability as candidates can be evaluated by their ability to reproduce some important features of the data, e.g., upper/lower bounds of the distribution, left/right tails of the distribution, shape of the distribution, and exact zero values (Hosking, 1997). The frequency-magnitude distributions used most commonly in hydrological studies can be categorized 15 into four groups: the normal family (Normal, LogNormal(LN)), General Extreme Value (GEV) family (Gumbel (GUM), Fréchet, and Weibull), Pearson III (P III) family (Gamma (GAM), Pearson III, and Log-Pearson III), and Generalized Pareto distribution (Wakeby) (Cunnane, 1989; Beven and Binley, 1992; Hosking, 1997; El Adlouni et al., 2008; Heo et al., 2008; Malamud and Turcotte, 2006; Salinas et al., 2014). Two types of widely accepted sampling methods (SMs) are the annual maximum (AM) and peak over threshold (POT) methods. Studies have shown that the return levels estimated by POT series

20 are usually higher than by AM series (Fisher and Tippett, 1928; Pickands, 1975; Madsen et al., 1997a, b). Another key source of uncertainty that should not be neglected is related to the method of parameterization. Based on probability weighted moments, developed by Greenwood et al. (1979) for obtaining closed-form estimates of distribution parameters, Hosking (1990) found that certain linear combinations of probability weighted moments, named L-moments (LMs), could measure the location, scale, and shape of probability distributions. LMs form the basis of a comprehensive theory for the

25 description, identification, and estimation of distributions (Liu and $\mathrm{Xu}, 2015$ ). Although moment-based methods are well established, it is sometimes difficult to assess the shape of a distribution conveyed by its moments, particularly when the sample is small (Hosking, 1997). Another common method is maximum likelihood (ML) estimation (Coles, 2001); however, it has a complex computation procedure.

Uncertainty assessment plays an important role in return-period-based decision making (Funtowicz and Ravetz, 1990). For 30 subjective method, such as the Pedigree Matrix (Barnett, 2006; Zhu et al., 2015), Carlo, Bayesian model averaging, and generalized likelihood methods (Vrugt et al., 2009; Tian et al., 2015), uncertainty estimation is often used for the approximation of the confidence intervals of quantiles of probability distributions (Coles and Pericchi, 2003; Parent and 
Hydrol. Earth Syst. Sci. Discuss., doi:10.5194/hess-2016-566, 2017

Manuscript under review for journal Hydrol. Earth Syst. Sci.

Published: 7 February 2017

(c) Author(s) 2017. CC-BY 3.0 License.

Bernier, 2003; Beven, 2006; Blasone et al., 2008; Xu et al., 2010; Bouda et al., 2011; Delsman et al., 2013; Cheng et al., 2014a; 2014b; 2015). However, these methods actually only test the uncertainty from parameterization and they have the limitation of to be affected greatly by the prior probability. Recently, the analysis of variance (ANOVA) approach has been applied to the quantitative assessment of uncertainties in studies of climate change and climate change impact (Bosshard et

5 al., 2013; Vetter et al., 2015). ANOVA is a model-based approach that partitions the total variance into components from different sources, allowing a fuller interpretation (Madden, 1976; Zwiers, 1987; 1996; Hingray et al., 2007). However, most current research focuses on the uncertainty analysis in one respect and few studies have considered the full scope of uncertainty during the process of return period estimation. Furthermore, although the hypothesis of stationarity in hydrological frequency analysis in a changing world has been questioned, it has not been given sufficient consideration in

10 related studies (Milly, 2008; Salas and Obeysekera, 2013; Serinaldi and Kilsby, 2015).

The Cuntan and Pingshan hydrological stations on the Yangtze River (China) have experienced different levels of human interference. In this study, long-term records of observed discharge from these stations were selected for the estimation of the uncertainty sources in the process of deducing the return period based on combinations of five DFs (GAM, GUM, LN, GEV, and P III), three PMs (method of moment (MOM), ML, and LM), and three extreme SMs (AM, POT, and Decadal

15 POT (DPOT)).

\section{Data and methods}

\subsection{Data}

The daily discharge records of the Cuntan and Pingshan hydrological stations on the Upper Yangtze River (Fig. 1), obtained from the "Hydrological Year Book-Yangtze" published by the Ministry of Water Resources in China, were selected for the analysis of the uncertainty in return period estimation (Jiang et al., 2007).

The drainage area of the Cuntan and Pingshan stations is about $8.6 \times 105$ and $4.8 \times 105 \mathrm{~km} 2$, respectively. The discharge at Cuntan, averaged over the period 1939-2012, was $39.9 \times 105$ m3 s-1 and that at Pingshan, averaged over the period 19402011, was $16.5 \times 105 \mathrm{~m} 3 \mathrm{~s}-1$. The maximum daily discharge was 84,300 (1 July 1981) and 28,600 m3 s-1 (16 September 1966) at Cuntan and Pingshan, respectively. Both stations have long-term observational records (over 70 years), but while 25 the discharge at Cuntan has shown a significant downward trend, that at Pingshan has shown only slight changes (Fig. 2). Comparison of the records of the two stations can give us a clue that how does the different population series affect the return period estimation results. 
Hydrol. Earth Syst. Sci. Discuss., doi:10.5194/hess-2016-566, 2017

\subsection{Sampling Methods}

Three SMs were considered in this study. One is block maximum approach, which consists of selected maximum within a block. Here, a one-year block was used to choose the annual maxima (AM) series. The second was the POT method, which chooses all extremes that exceed a given threshold (Davison and Smith, 1990; Madsen et al. 1997a; 1997b). Furthermore, considering the possibility that an extreme series might be changed significantly in a changing world, we established and applied the DPOT approach, which considers a 10-year period (i.e., a decade) as a block and applies the POT method to each block to sample the extremes.

\subsection{Distribution Functions}

Skewness and kurtosis are indicators of the shape of a sample series distribution. Skewness is the third moment of a data

10 series and it represents by how far the series deviates from a normal distribution. If skewness $=0$, the empirical probability density function (EPDF) follows a normal distribution; if skewness $>0$, the right-hand tail of the EPDF will be longer and become fatter as skewness increases (Groeneveld and Meeden, 1984; von Hippel, 2005; Cao et al., 2013). Kurtosis is the fourth moment of a data series and it represents the peakedness of the distribution. For a normal distribution, kurtosis $=3$; a distribution with a lower value of kurtosis has a heavy tail, which denotes that greater variance is attributable to frequent

15 extreme deviations (Westfall, 2014).

Considering different climatic and environmental backgrounds, regional optimistic distributions are used in different countries to analyze the frequency of hydrological extremes. For example, the Log-Pearson III distribution is recommended by the United States and Australia, the GUM distribution has been used in Canada and India, and the LN and Wakeby distributions have been applied in Japan and Korea (Water Resources Council, USA, 1982; Park et al., 2001; Öztekin, 2007;

20 El Adlouni et al., 2008;). Since the 1960s, the P III distribution, which is recommended by the Chinese Ministry of Water Resources (1995), has been used commonly in flood frequency analysis in China. Therefore, in this study, five distributions used worldwide in hydrological frequency analysis, namely GEV, P III, GAM, LN, and GUM were chosen to fit the extreme discharge series of the upper Yangtze River. GAM, LN, and GUM are two-parameter distributions, whereas GEV and P III are three-parameter distributions. Their probability density functions (PDFs) $f(x)$ and their cumulative distribution functions

(CDFs) $\mathrm{F}(\mathrm{x})$ are shown in Table 1.

\subsection{Parameterizations}

Different PMs might result in diverse quintile estimations. To evaluate the range of return levels using different parameterizations, three conventional approaches were applied to estimate the unknown parameters. These three methods are described briefly in the following. 
Hydrol. Earth Syst. Sci. Discuss., doi:10.5194/hess-2016-566, 2017

Manuscript under review for journal Hydrol. Earth Syst. Sci.

Published: 7 February 2017

(c) Author(s) 2017. CC-BY 3.0 License.

\subsubsection{MOM}

The shape of a probability distribution has traditionally been described by the moments of the distribution. Analogous quantities can be computed from an independent and identically distributed data sample $\left\{x_{1}, x_{2}, \ldots, x_{n}\right\}$. The moments are

$m_{r}^{\prime}=\frac{1}{n} \sum_{i=1}^{n} x_{i}, m_{1}^{\prime}=\bar{x}=$ mean,

5 and

$m_{r}=\frac{1}{n} \sum_{i=1}^{n}\left(x_{i}-\bar{x}\right)^{r}, m_{1}=0$,

where $n$ is the sample size.

The coefficient of variation $\left(C_{V}\right)$ is

$C_{v}=z=\frac{m_{2}^{1 / 2}}{m_{1}^{\prime}}$

10 The coefficient of skewness $\left(C_{S}\right)$ is

$C_{\mathrm{s}}=\gamma_{1}=\frac{n^{2}}{(n-1)(n-2)} \frac{m_{3}}{m_{2}^{3 / 2}}$.

\subsubsection{ML}

It is desirable to find an estimator $\theta$ as close to the true value $\theta_{0}$ as possible. Thus, $\theta$ is the function's variable and it is allowed to vary freely. The function of the likelihood can be structured as

$15 \quad L\left(x_{1}, x_{2}, \ldots, x_{n} ; \theta\right)=\prod_{i=1}^{n} f\left(x_{i} ; \theta\right) \quad(\theta \subseteq \varnothing)$.

In practice it is often more convenient to work with the logarithm of the likelihood function, called the log-likelihood:

$\ln L\left(x_{1}, x_{2}, \ldots, x_{n} ; \theta\right)=\prod_{i=1}^{n} \ln f\left(x_{i} ; \theta\right)$.

\subsubsection{LM}

In terms of probability weighted moments, LMs are given by:

$$
\left\{\begin{array}{c}
l_{1}=b_{0} \\
l_{2}=2 b_{1}-b_{0} \\
l_{3}=6 b_{2}-6 b_{1}+b_{0} \\
l_{4}=20 b_{3}-30 b_{2}+12 b_{1}-b_{0}
\end{array},\right.
$$


Hydrol. Earth Syst. Sci. Discuss., doi:10.5194/hess-2016-566, 2017

Manuscript under review for journal Hydrol. Earth Syst. Sci.

Published: 7 February 2017

(c) Author(s) 2017. CC-BY 3.0 License.
Hydrology and

Earth System

Sciences

Discussions

(c) $\underset{\mathrm{BY}}{(i)}$

where $b_{0}=\frac{1}{n} \sum_{i=1}^{n} x_{i}, b_{1}=\frac{1}{n} \sum_{i=2}^{n} \frac{i-1}{n-1} x_{i}, b_{2}=\frac{1}{n} \sum_{i=3}^{n} \frac{(i-1)(i-2)}{(n-1)(n-2)} x_{i}$, and $b_{3}=\frac{1}{n} \sum_{i=4}^{n} \frac{(i-1)(i-2)(i-3)}{(n-1)(n-2)(n-3)} x_{i}$.

The LM ratios are defined as follows:

$t_{2}=l_{2} / l_{1}, t_{3}=l_{3} / l_{2}, \ldots, t_{r}=l_{r} / l_{2} \quad(r=3,4, \ldots)$,

where $t_{2}$ is $L-C_{v}, t_{3}$ is L- skewness, and $t_{4}$ is $L$ - Kurtosis (Hosking 1990; 1997).

\section{$5 \quad 2.5$ Goodness of Fit Test}

The Chi-squared $\left(\chi^{2}\right)$ statistic is used to examine the distances between the distributions of features, and figures out if a sample comes from a hypothesized continuous distribution (Stanberry, 2013; Corder and Foreman, 2014). The hypothesis regarding the distributional form is rejected at the chosen significance level $(\alpha)$ if the test statistic is greater than the critical value. For a random sample $\left\{x_{l}, \ldots, x_{n}\right\}$, the following formula is used to define the number of bins $(\mathrm{k})$ :

$10 k=1+\log _{2} N$.

Then, the Chi-squared statistic can be defined as

$\chi^{2}=\sum_{i=1}^{k} \frac{\left(O_{i}-E_{i}\right)^{2}}{E_{i}}$

where $O_{i}$ is the observed frequency for bin $i$, and $E_{i}$ is the expected frequency for bin $i$, which can be calculated by

$E_{i}=F\left(x_{2}\right)-F\left(x_{1}\right)$,

15 where $F$ is the CDF of the probability distribution being tested, and $x_{1}$ and $x_{2}$ are the limits for bin $i$.

\subsection{Method of Uncertainty Assessment}

The ANOVA method was used to partition the variance of uncertainty (Von Storch and Zwiers, 2001; Deque et al., 2007; Yip et al., 2011). The framework of the three-way ANOVA used in the current study is depicted in Fig. 3. The different sample sizes of the uncertainty sources (three SMs, five DFs, and three PMs) might result in a biased variance estimation,

20 which can be avoided using a subsampling scheme (Bosshard et al., 2013; Vetter et al., 2015). Here, subsampling was conducted to guarantee that each subsample had three distributions, three sample methods, and three parameter methods $(3 \times$ $3 \times 3$ ). The unbiased variance fractions $\eta^{2}$ related to different components can be calculated as

$$
\eta_{x}^{2}=\frac{1}{10} \sum_{d=1}^{10} \frac{S S_{x}(m)}{\operatorname{TSS}(m)},
$$

where $\operatorname{TSS}(m)$ is the total sum of the squares (TSS) of each subsample. The TSS is defined as

$25 T S S=\sum_{i=1}^{3} \sum_{j=1}^{3} \sum_{k=1}^{5}\left(Y_{i j k}-\bar{Y}_{o o o}\right)^{2}$, 
Hydrol. Earth Syst. Sci. Discuss., doi:10.5194/hess-2016-566, 2017

Manuscript under review for journal Hydrol. Earth Syst. Sci.

Published: 7 February 2017

where $Y_{i j k}$ is the particular value corresponding to $\mathrm{SM} i, \mathrm{PM} j$, and $\mathrm{DF} k$, respectively; and $Y_{\text {ooo }}$ is the overall mean. The ANOVA can split the total sum of the squares into the sums of the squares due to the individual effects $\left(S S_{\text {Data }}, S S_{\text {Param }}, S S_{\text {Dis }}\right)$.

\section{Results}

\subsection{Statistical Characteristics of Extreme Series}

5 The EPDFs of AM, POT, and DPOT in the upper Yangtze River are shown in Fig. 4. For Cuntan, the skewness and kurtosis of the AM, POT, and DPOT series are 0.40 and $0.41,1.76$ and 5.25, and 1.12 and 3.10, respectively. The EPDF of the AM series has the heaviest tail and that of the POT series has the longest tail.

Discharge at Pingshan has no significant trend over time. The kurtosis of its extreme series does not show any significant difference among the three SMs. The Skewness of its AM series is 0.61 (slightly higher than Cuntan) and its kurtosis is 0.48

10 (comparable with Cuntan). The skewness and kurtosis of Pingshan's POT series are 1.21 and 1.85, respectively; much lower than Cuntan. The skewness and kurtosis of the DPOT series are 0.68 and 0.81 , respectively; the kurtosis is lower than Cuntan.

\subsection{Goodness of Fit of Distributions}

The $\chi^{2}$ test was applied to examine the goodness of fit (GOF) of the five distributions for fitting the upper Yangtze River hydrological extremes. A low value of the $\chi^{2}$ statistic indicates smaller differences between the theoretical PDF and EPDF. The results of the $\chi^{2}$ test statistics for the 45 combinations of SMs, DFs, and PMs are shown in Fig. 5. For the Cuntan discharge, except for the fitting of GEV to the POT series by the ML method, which fails to pass the $\chi 2$ GOF test (at the 0.05 significance level), all the fitting results from the other 44 combinations are satisfactory (Fig. 5a). For the Pingshan discharge, all 45 results pass the $\chi 2$ test at the 0.05 significance level (Fig. 5b).

20 The variances of the fitting results of the SMs are shown in the averaged $\chi^{2}$ statistics of the 15 combinations fitted by the different DFs (GAM/GUM/LN/P III/GEV) and PMs (ML/LM/MOM) for each SM in Fig. 5a and 5b. It is clear that for both stations the statistics of the DPOT-based combinations are smallest. This suggests that the DPOT sequence can be described well by all five selected DFs using all three PMs, but that the optimum way to deduce return levels for the DPOT series for both stations is the LM-GAM combination. For the AM series, the combinations of LM-GAM and ML-P III are optimum for Cuntan and Pingshan, respectively. For the POT series, the ML-P III combination is optimum for both stations. For all three extreme series at Pingshan, the fitting results from the combination of the LN distribution using LM parameterization are the worst. For the Cuntan extremes, the LM-LN combination is the worst choice for the AM series, ML-GEV is the worst for the POT series, and MOM-GAM is the worst for the DPOT series. 
Hydrol. Earth Syst. Sci. Discuss., doi:10.5194/hess-2016-566, 2017

Manuscript under review for journal Hydrol. Earth Syst. Sci.

Published: 7 February 2017

(c) Author(s) 2017. CC-BY 3.0 License.

To illustrate the effects of the DFs on the fitting results, the averaged $\chi^{2}$ statistics of nine combinations of SMs (AM/POT/DPOT) and PMs (ML/LM/MOM) fitted by each function are shown in Fig. 5c and 5d. Of the five distributions, the three-parameter distributions (P III and GEV) fit better than the two- parameter distributions (LN, GUM, and GAM) and the fitting result of the LN distribution are the worst. For the Cuntan extreme series, GAM is the optimum distribution, followed by the P III distribution. The averaged $\chi 2$ statistics of the GEV-based combinations are higher than the GAM-based combinations, and except for the poorer fit of the GEV-POT-ML combination, the GEV-based fittings are even better than the GAM-based results. For the Pingshan extreme series, P III is the optimum distribution, followed by the GEV distribution. The LN and GUM distributions do not fit the POT series well.

The variabilities of the averaged $\chi^{2}$ statistics for the three PMs are relatively smaller than for the SMs and DFs. The $\chi^{2}$

10 statistics of the LM-based fitting results are higher than the ML- and MOM-based fittings, and this variance is higher at Pingshan than Cuntan (Fig. 5c and 5d). For the Cuntan extreme series, the $\chi 2$ statistics are smallest for GAM-DPOT, P IIIPOT, and LN-DPOT using LM, ML, and MOM, respectively. The largest $\chi 2$ statistics are obtained using the LN-AM, GEV-POT, and GUM-AM combinations with the LM, ML, and MOM methods, respectively. For the Pingshan extreme series, the smallest $\chi 2$ statistics are derived with P III-POT using the ML and LM methods, and with the GAM-DPOT

15 combinations using MOM. The largest $\chi^{2}$ statistics are obtained with LN-POT combinations using ML and LM and by GAM-POT combinations using MOM (Fig. 5a and 5b).

\subsection{Uncertainty Range of Return Period Events}

The estimation of T-year return period events using all 45 combinations of the 3 SMs, 5 DFs, and 3 PMs shows that large variability can be found in the return levels. Figure 6 indicates that the range of return levels by the nine LN-based combinations is the largest, while that of the nine P III-based combinations is the smallest among the five distributions used. Note that because of the poor performance of the POT-ML-GEV combination, the range of return levels estimated by the GEV distribution is also very large for the Cuntan extremes. The return levels estimated by the DPOT method show steady performance for all PM and DF combinations, with the smallest range of return levels compared with other SMs. The return levels estimated by the three PMs are very similar.

25 For Cuntan, the 20-year return period event deduced by the 45 combinations ranges from $63,800.8$ to $74,024.1 \mathrm{~m}^{3} \mathrm{~s}^{-1}$; the variance of $10,223.3 \mathrm{~m}^{3} \mathrm{~s}^{-1}$ is about $15 \%$ of the average level $\left(66,808.2 \mathrm{~m}^{3} \mathrm{~s}^{-1}\right)$. The 50 -year event ranges from $66,716.2$ to $83,115.0 \mathrm{~m}^{3} \mathrm{~s}^{-1}$; the variance of $16,398.8 \mathrm{~m}^{3} \mathrm{~s}^{-1}$ is $23 \%$ of the average level $\left(71,995.1 \mathrm{~m}^{3} \mathrm{~s}^{-1}\right)$. The 100 -year event ranges from $68,707.4$ to $89,787.8 \mathrm{~m}^{3} \mathrm{~s}^{-1}$; the variance of $21,080.4 \mathrm{~m}^{3} \mathrm{~s}^{-1}$ is $28 \%$ of the average level $\left(75,845.2 \mathrm{~m}^{3} \mathrm{~s}^{-1}\right)$. The 200 -year event ranges from $70,563.4$ to $97,661.5 \mathrm{~m}^{3} \mathrm{~s}^{-1}$; the variance of $27,098.1 \mathrm{~m}^{3} \mathrm{~s}^{-1}$ is about $34 \%$ of the average level $\left(79,617.8 \mathrm{~m}^{3} \mathrm{~s}^{-1}\right)$.

30 The 500 -year event ranges from $72,855.9$ to $112,444.0 \mathrm{~m}^{3} \mathrm{~s}^{-1}$; the variance of $39,588.1 \mathrm{~m}^{3} \mathrm{~s}^{-1}$ is $47 \%$ of the average level 
Hydrol. Earth Syst. Sci. Discuss., doi:10.5194/hess-2016-566, 2017

Manuscript under review for journal Hydrol. Earth Syst. Sci.

Published: 7 February 2017

(c) Author(s) 2017. CC-BY 3.0 License.

$\left(84,278.7 \mathrm{~m}^{3} \mathrm{~s}^{-1}\right)$. The 1000 -year event ranges from $74,492.5$ to $125,658.0 \mathrm{~m}^{3} \mathrm{~s}^{-1}$; the variance of $51,165.5 \mathrm{~m}^{3} \mathrm{~s}^{-1}$ is $58 \%$ of the average level $\left(88,240.2 \mathrm{~m}^{3} \mathrm{~s}^{-1}\right)$ (Fig. 6a).

The estimated ranges of return level events at Pingshan are smaller than at Cuntan. The 20-year return period event estimated by the 45 combinations ranges from $23,097.8$ to $25,595.3 \mathrm{~m}^{3} \mathrm{~s}^{-1}$; the variance of $2497.5 \mathrm{~m}^{3} \mathrm{~s}^{-1}$ is about $11 \%$ of the average

5 return level $\left(23,761.3 \mathrm{~m}^{3} \mathrm{~s}^{-1}\right)$. The 50 -year event ranges from $24,250.6$ to $28,740 \mathrm{~m}^{3} \mathrm{~s}^{-1}$; the variance of $4489.4 \mathrm{~m}^{3} \mathrm{~s}^{-1}$ is about $17 \%$ of the average level $\left(25,710.4 \mathrm{~m}^{3} \mathrm{~s}^{-1}\right)$. The 100-year event ranges from $25,039.6$ to $31,048.3 \mathrm{~m}^{3} \mathrm{~s}^{-1}$; the variance of $6008.7 \mathrm{~m} \mathrm{~s}^{3} \mathrm{~s}^{-1}$ is about $22 \%$ of the average level $\left(27,123.7 \mathrm{~m}^{3} \mathrm{~s}^{-1}\right)$. The 200 -year event ranges from $25,776.2$ to $33,323.0 \mathrm{~m}^{3} \mathrm{~s}^{-1}$; the variance of $7546.8 \mathrm{~m}^{3} \mathrm{~s}^{-1}$ is about $26 \%$ of the average return level $\left(28,502.0 \mathrm{~m}^{3} \mathrm{~s}^{-1}\right)$. The 500 -year event ranges from $26,687.6$ to $37,604.3 \mathrm{~m}^{3} \mathrm{~s}^{-1}$; the variance of $10,916.7 \mathrm{~m}^{3} \mathrm{~s}^{-1}$ is about $36 \%$ of the average level $\left(30,288.1 \mathrm{~m}^{3} \mathrm{~s}^{-1}\right)$. The 1000 -

10 year event ranges from $27,339.2$ to $41,718.1 \mathrm{~m}^{3} \mathrm{~s}^{-1}$; the variance of $14,378.9 \mathrm{~m}^{3} \mathrm{~s}^{-1}$ is about $45 \%$ of the average level $\left(31,621.9 \mathrm{~m}^{3} \mathrm{~s}^{-1}\right)$ (Fig. 6b).

\subsubsection{Return Level Variation based on Different Samplings}

To analyze the range of different SMs, return period events estimated by the combinations of the five DFs (GEV/P III/GAM/GUM/LN) and three PMs (ML/LM/MOM) were averaged for each SM (Fig. 7a1 and 7b1). The range of averaged

15 return levels estimated using the different SMs shows an increasing trend from shorter to longer return period events.

For the Cuntan discharge, the average return levels of 20-1000-year events are 68,085.71-92,436.35, 65,862.59-87,633.27, and $66,176.39-\sim 84,654.03 \mathrm{~m}^{3} \mathrm{~s}^{-1}$ for the AM, POT, and DPOT series, respectively. The range of return levels estimated by the different SMs is $2223.1-7785.3 \mathrm{~m}^{3} \mathrm{~s}^{-1}$ for the $20-1000$-year events, which is about $3 \%-8 \%$ of the averaged return level over the three SMs (Fig. 7a1). For the Pingshan discharge, the average return levels of 20-1000-year events are 23,675.05-

$2032,755.79,23,688.6-31,304.66$, and 23,920.25-30,805.37 $\mathrm{m}^{3} \mathrm{~s}^{-1}$ based on AM, POT, DPOT samples, respectively. The changes of estimated return period extremes by the different SMs at Pingshan are obviously smaller than at Cuntan, with values ranging from 403.7 to $1324.6 \mathrm{~m}^{3} \mathrm{~s}^{-1}$ for $20-1000$-year events, which are about $2 \%-4 \%$ of the averaged return level over the three SMs (Fig. 7b1).

\subsubsection{Return Level Variation based on Different Parameterizations}

25 Return period events estimated by the combinations of five DFs (GAM/GUM/LN/P III/GEV) and three SMs (AM/POT/DPOT) were averaged over each PM (Fig. 7a2 and 7b2).

For the Cuntan discharge, the return levels by the three PMs are similar, ranging between 697.8 and $2360.4 \mathrm{~m}^{3} \mathrm{~s}^{-1}$ for 20 1000 -year events, which are about $1 \%$ and $3 \%$ of the averaged return levels over the three PMs. The average of return period events of MOM-based combinations is the smallest among the three parameterizations, with a value of 66,359.6-86,978.6 $\mathrm{m}^{3}$ $30 \mathrm{~s}^{-1}$ for $20-1000$-year events. The return levels estimated by LM are the largest for events shorter than 200 years, whereas 
Hydrol. Earth Syst. Sci. Discuss., doi:10.5194/hess-2016-566, 2017

Manuscript under review for journal Hydrol. Earth Syst. Sci.

Published: 7 February 2017

(c) Author(s) 2017. CC-BY 3.0 License.

those estimated by ML-combinations are the largest for events longer than 200 years. The average of the 15 LM- and MLbased combinations is $67,057.4-88,403.1$ and $66,707.7-89,399.0 \mathrm{~m}^{3} \mathrm{~s}^{-1}$ for 20- and 1000-year events, respectively (Fig. 7a2).

For the Pingshan series, the ranges of the return levels derived by the three PMs are larger than for Cuntan, with values of $245.2-1950.4 \mathrm{~m}^{3} \mathrm{~s}^{-1}$ for $20-1000$-year events, respectively, i.e., about $1 \%-6 \%$ of the averaged return levels over the three

5 PMs. The average return levels estimated by MOM are also the smallest, with values of 23,920.3-30,805.4 $\mathrm{m}^{3} \mathrm{~s}^{-1}$ for 20 1000-year events, while the LM-based combinations have the largest average return levels with values of 23,675.1-32,775.8 $\mathrm{m}^{3} \mathrm{~s}^{-1}$ for 20-1000-year events. For the ML-based combinations, the average return levels of all 15 LM-based combinations are 23,688.6-31,304.66 $\mathrm{m}^{3} \mathrm{~s}^{-1}$ for 20-1000-year events (Fig. 7b2).

\subsubsection{Return Level Variation based on Different Distributions}

10 The range of averaged return levels of the nine combinations of three SMs (AM/POT/DPOT) and three PMs (ML/LM/MOM) over each of the five DFs is greater than for the PM- and SM-based results (Fig. 7a3 and 7b3).

For the Cuntan discharge, the results of GUM-based combinations have the largest return levels among the five functions, with values of $66,952.6-92,751.8 \mathrm{~m}^{3} \mathrm{~s}^{-1}$ for 20-1000-year events. The average return levels of the GAM-based combinations are the smallest, with values ranging from $65,532.9-80,719.4 \mathrm{~m}^{3} \mathrm{~s}^{-1}$ for $20-1000$-year events. The range of the five DFs is

15 between 1767.4 and $12,032.4 \mathrm{~m}^{3} \mathrm{~s}^{-1}$ for $20-1000$-year events, which is about $3 \%-14 \%$ of the averaged return level over the five DFs (Fig. 7a3).

A similar pattern is found for the Pingshan extremes. The results of the GAM-based combinations have the smallest return levels for all five functions, with values of 23,344.6-29,009.2 $\mathrm{m}^{3} \mathrm{~s}^{-1}$ for 20-1000-year events. The return levels of the GUMbased combinations have the largest average return levels, with values of 23,860.6-33,415.8 $\mathrm{m}^{3} \mathrm{~s}^{-1}$ for 20-1000-year events.

20 The range of the five DFs is between 664.7 and $4406.6 \mathrm{~m}^{3} \mathrm{~s}^{-1}$ for $20-1000$-year events, which is about $3 \%-14 \%$ of the averaged return level over the five DFs (Fig. 7b3).

\subsection{Evaluation of Uncertainty Contribution}

The ANOVA method was used to decompose the total uncertainty into different sources. The total sum of the squares increases with increasing return period, but the contributions from the different sources to the overall uncertainty might 25 change over the return period. Figure 8 shows the contributions from the different sources (SMs, DFs, and PMs) to the overall uncertainty.

For the Cuntan discharge, the SMs contribute more than $40 \%$ of the total uncertainty in the estimation of return levels, and this changes little for 20-1000-year event estimations. The DFs also exert obvious influence on the return period estimation, 
Hydrol. Earth Syst. Sci. Discuss., doi:10.5194/hess-2016-566, 2017

Manuscript under review for journal Hydrol. Earth Syst. Sci.

contributing about $30 \%-40 \%$ of the total uncertainty, and this uncertainty increases with time. The PMs contribute the least to the uncertainty, accounting for about $10 \%-20 \%$ of the total.

A different pattern can be seen for the uncertainty of return period estimation at Pingshan. The DFs are the dominant source, explaining almost $50 \%$ of the total uncertainty, and this is constant over time. The SMs contribute about $22 \%-35 \%$ of the total uncertainty, and this proportion increases with the return period. Uncertainty originating from the PMs is the least important individual source of uncertainty at Pingshan (but more pronounced than that at Cuntan), contributing about 17\%$33 \%$ of the total uncertainty, and this proportion decreases with the return period.

\section{Discussion and Concluding Remarks}

This study used daily discharge monitored at the Cuntan (which had a significant trend of discharge) and Pingshan (which

10 had no obvious trend of discharge) hydrological stations on the upper Yangtze River in China to compare the return period events estimated by different SMs (AM/POT/DPOT), DFs (GAM/GUM/LN/GEV/P III) and PMs (ML/LM/MOM). The contributions of the SMs, PMs, and DFs to the total uncertainty of the return period estimations was analyzed using the ANOVA method.

A large variability of return period events was estimated by the 45 different combinations. For Cuntan, the range of return

15 levels was about $15 \%$ of the average $\left(66,808.2 \mathrm{~m}^{3} \mathrm{~s}^{-1}\right)$ for 20 -year events and up to $58 \%$ of the average $\left(88,240.2 \mathrm{~m}^{3} \mathrm{~s}^{-1}\right)$ for 1000-year events. The ranges of return levels estimated by all 45 combinations at Pingshan were smaller than at Cuntan. For $20-1000$-year events, the ranges of return levels were about $11 \%-45 \%$ of the average return level $\left(23,761.3-31,621.9 \mathrm{~m}^{3} \mathrm{~s}^{-1}\right)$.

The selection of SMs, DFs, and PMs clearly affected the return period estimations. The ranges of the averaged return levels of the three different PMs were similar, but those of the five DFs were the largest. The SMs caused intermediate variation of the return levels but with larger differences at Cuntan than at Pingshan.

The ranges of return levels estimated by two-parameter DFs (GAM, GUM, and LN) were larger than estimated by threeparameter DFs. According to the GOF test, the worst fitting LN distribution had the largest range of return levels, whereas the best fitting P III distribution had the smallest range. Note that because of the poor performance of the POT-ML-GEV combination, the range of return levels estimated with the GEV distribution was also very large for the Cuntan extremes.

25 This indicates that it is not only the individual factors but also the interaction of the SMs, PMs, and DFs that affects the uncertainty of the return period estimation. The return levels estimated by the DPOT method demonstrated steady performance for every combination of PM and DF, with the smallest range of return levels in comparison with the other SMs.

The results of the ANOVA analysis showed that all modeling chain combinations had an increasing trend of the total sum of the squares with increasing return periods, but that the contributions of the different sources were different. Although the 
Hydrol. Earth Syst. Sci. Discuss., doi:10.5194/hess-2016-566, 2017

largest range of return levels stemmed from the DFs for both the Cuntan and the Pingshan discharge series, as the number of DFs used in this study was greater than the SMs and PMs, after the subsampling scheme, the main sources of uncertainty associated with return level estimation at the different stations were different. For Cuntan, which showed obvious change, the SMs had the greatest influence on the return levels, contributing more than $40 \%$ of the total uncertainty; however, for

5 Pingshan, the DF was the most important source of uncertainty, contributing almost $50 \%$ of the total. The proportion of the contribution of the PMs to the total uncertainty is less significant than that of the SMs and DFs, but it plays a more important role in the Cuntan discharge series than the Pingshan series. This indicates that the sources of uncertainty in the return period estimations are different for discharges with and without significant trends, and that multiple uncertainty sources in the estimations of return periods should be considered to meet the demands of different planning purposes.

10 Through a case-dependent uncertainty analysis in this study, it was found that the selection of different methods has significant effects on return period estimations. An estimation return period is an approximated figure and thus, some degree of uncertainty remains in the process. There are two possible ways to reduce the associated uncertainty. The first is to obtain a sufficiently long and high-quality extreme series, as in Parent and Bernier (2003), who highlighted that the incorporation of historical records and regional information into the process of deducing return periods is useful for uncertainty reduction.

15 Unfortunately, reliable data are not always available, and therefore choosing better SMs is the more viable alternative. This study found that of the three SMs the DPOT method brought the least variation. The ranges of return levels based on the DPOT series were usually the smallest compared with the other two sampling series, and therefore it was considered suitable for sampling discharge time series with or without significant trends. Furthermore, it also performed best when applying different DFs and PMs. Several studies have recommended a nonstationary method to reduce the uncertainties in a changing

20 world, by applying time-dependent distribution parameters. However, the application of these models remains immature and the hypothesis that "stationarity is dead" remains debatable (Milly et al., 2008; Salas and Obeysekera, 2013; Cheng et al., 2014; Serinaldi and Kilsby, 2015). For a station that has significant trends, the application of DPOT sampling might be one way to reduce uncertainty in return period estimations.

The second option is to reduce the uncertainty in the return period estimation processes is using more candidate DFs, and 25 then by choosing an optimum DF to reduce the total uncertainty. In this study, the P III distribution performed well at both stations and the ranges of the return levels of the P III-based combinations were the smallest. However, it must be noted that the DF itself, as well as the interaction of the DF with the SMs and PMs, contributes to the uncertainty in the return period estimation. The GEV is recommended by the WMO to fit annual climate extremes (Klein Tank et al., 2009). However, it failed to pass the GOF test when fitting the Cuntan POT series by the MLE method, although other GEV-based 30 combinations did fit the extreme discharge series very well (Botero and Francés, 2010; Salinas et al., 2014). In addition, Hosking (1997) indicated that the return period estimated by two-parameter distributions would be accurate only when the fitted distribution approximated the true distribution; otherwise, it could be severely biased. The results of this study also 
Hydrol. Earth Syst. Sci. Discuss., doi:10.5194/hess-2016-566, 2017

Manuscript under review for journal Hydrol. Earth Syst. Sci.

Published: 7 February 2017

(c) Author(s) 2017. CC-BY 3.0 License.

suggested that the ranges of return periods estimated by the three-parameter distributions were smaller than those of the twoparameter distributions, and that the three-parameter distributions were more reliable in the frequency analysis of extremes. Therefore, results derived from two-parameter DFs should be treated with caution in practice.

As mentioned in the introduction, many distributions have been used in return period estimations (Park et al., 2001; Öztekin,

5 2007; Su et al., 2009; Fischer et al., 2012). The selection of only five distributions is one of the primary limitations of the current study. The uncertainty ranges enlarged with increasing return periods. To achieve different goals, different sources of uncertainty should be considered when estimating return levels, especially with respect to the desired frequency when estimating the return levels. Considering the weights of uncertainties in return level estimations, reasonable SMs and DFs should be selected carefully in future hydraulic design and risk management practices, according to the level of return

10 periods required.

\section{Acknowledgments}

This research was supported by the National 1000 Talent program (Y474171), the National Basic Research Program of China (973 Program) (2013CB430205), the National Natural Science Foundation of China (41571494, 41375099, 91337108, 41561124014). Many thanks to the anonymous reviewers who supplied useful suggestions and helped to significantly

15 improve this manuscript. Furthermore, we are thankful to J. L. Huang for valuable discussions, and T. Vetter for introduction of the ANOVA method.

\section{References}

AghaKouchak, A, and Nasrollahi, N: Semi-parametric and parametric inference of extreme value models for rainfall data, Water Resour. Manag., 24(6), 1229-1249, 2010.

20 Barnett, D. N., Brown, S. J., Murphy, J. M., Sexton, D. M., and Webb, M. J.: Quantifying uncertainty in changes in extreme event frequency in response to doubled CO2 using a large ensemble of GCM simulations, Clim. Dynam., 26(5), 489$511,2006$.

Beck, M. B.: Water quality modeling: a review of the analysis of uncertainty, Water Resour. Res., 23(8), 1393-1442, 1987.

Beven, K.: A manifesto for the equifinality thesis, J. Hydrol., 320(1-2), 18-36, 2006.

25 Beven, K., and Binley, A.: The future of distributed models: model calibration and uncertainty prediction, Hydol. Process., 6(3), 279-298, 1992.

Blasone, R. S., Vrugt, J. A., Madsen, H., Rosbjerg, D., Robinson, B. A., and Zyvoloski, G. A: Generalized likelihood uncertainty estimation (GLUE) using adaptive Markov Chain Monte Carlo sampling, Adv. Water Resour., 31(4), 630$648,2008$. 
Hydrol. Earth Syst. Sci. Discuss., doi:10.5194/hess-2016-566, 2017

Manuscript under review for journal Hydrol. Earth Syst. Sci.

Published: 7 February 2017

(c) Author(s) 2017. CC-BY 3.0 License.

Bosshard, T., Carambia, M., Goergen, K., Kotlarski, S., Krahe, P., Zappa, M., and Schär, C: Quantifying uncertainty sources in an ensemble of hydrological climate - impact projections, Water Resour. Res., 49(3), 1523-1536, 2013.

Botero, B. A., and Francés, F.: Estimation of high return period flood quantiles using additional non-systematic information with upper bounded statistical models, Hydrol. Earth Syst. Sci., 14(12), 2617-2628, 2010.

5 Bouda, M., Rousseau, A. N., Konan, B., Gagnon, P., and Gumiere, S. J.: Bayesian uncertainty analysis of the distributed hydrological model HYDROTEL, J. Hydrol. Eng., 17(9), 1021-1032, 2011.

Cao, L. G., Zhong, J., Su, B. D., Zhai, J. Q., and Gemmer, M.: Probability distribution and projected trends of daily precipitation in China, Adv. Climate Change Res., 4(3), 153-159, 2013.

Cheng, L., and AghaKouchak, A.: Nonstationary precipitation Intensity-Duration- Frequency curves for infrastructure design in a changing climate, Sci. Rep., 4, 7093, 2014a.

Cheng, L., AghaKouchak, A., and Gilleland Katz, E. R. W: Non-stationary extreme value analysis in a changing climate, Climatic Change, 127(2), 353-369, 2014b.

Cheng, L., Phillips, T. J., and AghaKouchak, A.: Non-stationary return levels of CMIP5 multi-model temperature extremes, Clim. Dynam., 44(11-12), 2947-2963, 2015.. doi: 10.1007/s00382-015-2625-y

15 Chinese Ministry of Water Resources: Standard for Flood Control, GB50201, 19pp, 1995. (in Chinese)

Coles, S., Pericchi, L. R., and Sisson, S.: A fully probabilistic approach to extreme rainfall modeling, J. Hydrol., 273(1), 3550, 2003.

Corder ,G. W., and Foreman D. I.: Nonparametric statistics: a step-by-step approach, John Wiley \& Sons, 2014.

Cunnane, C.: Statistical distributions for flood frequency analysis, Operational Hydrology Report (WMO), 44(11), 369-369, 1989.

Coles, S., Bawa, J., Trenner, L., and Dorazio, P.: An introduction to statistical modeling of extreme values, London: Springer, 2001.

Cooley, D., Nychka, D., and Naveau, P.: Bayesian spatial modeling of extreme precipitation return levels, J. Am. Stat. Assoc., 102(479), 824-840, 2007.

25 Davison, A. C., and Smith, R. L.: Models for exceedances over high thresholds, J. R. Stat. Soc. B, 52(3), 393-442, 1990.

Delsman, J. R., Essink, G. H., Beven, K. J., and Stuyfzand, P. J.: Uncertainty estimation of end - member mixing using generalized likelihood uncertainty estimation (GLUE), applied in a lowland catchment, Water Resour. Res., 49(8), 4792-4806, 2013.

Déqué, M., Rowell, D. P., Lüthi, D., Giorgi, F., Christensen, J. H., Rockel, B., Jacob, D., Kjellström, E., de , M., and van den Hurk, B.: An intercomparison of regional climate simulations for Europe: assessing uncertainties in model projections, Climatic Change, 81(1), 53-70, 2007.

El Adlouni, S., Bobée, B., and Ouarda, T. B. M. J.: On the tails of extreme event distributions in hydrology, J. Hydrol., 355(1), 16-33, 2008. 
Hydrol. Earth Syst. Sci. Discuss., doi:10.5194/hess-2016-566, 2017

Manuscript under review for journal Hydrol. Earth Syst. Sci.

Published: 7 February 2017

(c) Author(s) 2017. CC-BY 3.0 License.

Fischer, T., Su, B. D., Luo, Y., and Scholten, T.: Probability distribution of precipitation extremes for weather index-based insurance in the Zhujiang River Basin, South China, J. hydrometeorol., 13(3), 1023-1037, 2012.

Fisher, R. A., Tippett, L. H. C.: Limiting forms of the frequency distribution of the largest or smallest member of a sample, Math. Proc. Cambridge, 24(2), 180-190, 1928.

5 Funtowicz, S. O., and Ravetz, J. R.: Science for Policy: Uncertainty and Quality. Uncertainty and quality in science for policy $15,7-16,1990$.

Greenwood, J. A., Landwehr, J. M,. Matalas, N. C., and Wallis, J. R.: Probability weighted moments: definition and relation to parameters of several distributions expressable in inverse form, Water Resour. Res., 15(5), 1049-1054, 1979.

Groeneveld, R. A., and Meeden, G.: Measuring skewness and kurtosis, The Statistician, 33(4), 391-399, 1984.

10 Hingray, B., Mezghani, A., and Buishand, T.: Development of probability distributions for regional climate change from uncertain global mean warming and an uncertain scaling relationship. Hydrol. Earth Syst. Sci., 11(3), 1097-1114, 2007.

Hoffman, F. O., and Hammonds, J.S.: Propagation of uncertainty in risk assessments: the need to distinguish between uncertainty due to lack of knowledge and uncertainty due to variability, Risk Anal., 14(5), 707-712, 1994.

Horton, R. E.: Discussion on flood flows trans, ASCE, 77, 663-670, 1914.

15 Hosking, J. R. M.: L-moments: Analysis and estimation of distributions using linear combinations of order statistics. J. R. Stat. Soc. B, 52(1), 105-124, 1990.

Hosking, J. R. M., and Wallis, J. R.: Regional Frequency Analysis: An Approach Based on L-Moments. Cambridge University Press, 242 pp, 1997.

IPCC, Field, C.B, Barros ,V. R., Dokken, D. J., Mach, K. J., Mastrandrea, M. D., Bilir, T. E., Chatterjee, M., Ebi, K. L., Estrada, Y. O., Genova, R. C., Girma, B., Kissel, E. S., Levy, A. N., MacCracken, S., Mastradrea, P. R., and White, L. L. (eds.): Climate Change 2014: Impacts, adaptation, and vulnerability. (Part. A). Global and sectoral aspects. Contribution of working group II to the fifth assessment report of the intergovernmental panel on climate change Cambridge University Press, Cambridge, United Kingdom and New York, NY, USA, 1132pp, 2014.

Jiang, T., Su, B. D., and Hartmann, H.: Temporal and spatial trends of precipitation and river flow in the Yangtze River Basin, 1961-2000, Geomorphology, 85(3), 143-154, 2007.

Heo, J. H., Kho, Y. W., Shin, H., Kim, S., and Kim, T.: Regression equations of probability plot correlation coefficient test statistics from several probability distributions, J. Hydrol., 355(1), 1-15, 2008.

Kay, A. L., Davies, H. N., Bell, V. A., Jones, R. G.: Comparison of uncertainty sources for climate change impacts: flood frequency in England, Climatic Change, 92(1-2), 41-63, 2009.

30 Kianfar, B., Fatichi, S., Paschalis, A., Maurer, M., and Molnar, P.: Climate change and uncertainty in high-resolution rainfall extremes, Hydrol. Earth Syst. Sci. Discuss., doi:10.5194/hess-2016-536, 2016

Klein Tank, A. M. G., Zwiers, F. W., and Zhang, X. B.: Guidelines on analysis of extremes in a changing climate in support of informed decisions for adaptation. World Meteorological Organization Tech. Doc. WMO-TD 1500, WCDMP-No. 72, $52 \mathrm{pp}, 2009$. 
Hydrol. Earth Syst. Sci. Discuss., doi:10.5194/hess-2016-566, 2017

Manuscript under review for journal Hydrol. Earth Syst. Sci.

Liu, L., and Xu, Z. X.: Regionalization of precipitation and the spatiotemporal distribution of extreme precipitation in southwestern China, Nat. Hazards, 80(2), 1195-1211, 2015.

Madden, R.: Estimates of the natural variability of time-averaged sea-level pressure, Mon. Weather Rev., 104, 942-952, 1976.

5 Madsen, H., Pearson, C. P., and Rosbjerg, D.: Comparison of annual maximum series and partial duration series methods for modeling extreme hydrologic events: 1. At-site modeling, Water Resour. Res., 33(4), 747-757, 1997a.

Madsen, H., Pearson, C. P., Rosbjerg, D.: Comparison of annual maximum series and partial duration series methods for modeling extreme hydrologic events: 2. Regional modeling, Water Resour. Res., 33(4), 759-769, 1997b.

Malamud, B. D., and Turcotte, D. L.: The applicability of power-law frequency statistics to floods, J. Hydrol., 322(1), 168180, 2006.

Milly, P. C. D, Wetherald, R. T., Dunne, K. A., and Delworth, T. L.: Increasing risk of great floods in a changing climate, Nature, 415(6871), 514-517, 2002.

Milly, P. C. D., Julio, B., Malin, F., Hirsch, R. M., Kundzewicz, Z. W., and Lettenmaier, D. P.: Stationarity is dead: whither water management?, Science, 319(5863), 573-574, 2008.

15 Öztekin, T.: Wakeby distribution for representing annual extreme and partial duration rainfall series. Meteorol. Appl., 14(4), 381-387, 2007.

Parent, E., and Bernier, J.: Bayesian POT modeling for historical data, J. Hydrol., 274(1), 95-108, 2003.

Park, J. S., Jung, H. S., Kim, R. S., and Oh, J. H.: Modelling summer extreme rainfall over the Korean peninsula using Wakeby distribution, Int. J. Climatol., 21(11), 1371-1384, 2001.

20 Pickands, III J.: Statistical inference using extreme order statistics, Ann. Stat., 3(1), 119-131, 1975.

Qin, D. H., Ding, Y. J., Mu, M., eds.: Climate and Environmental Change in China: 1951-2012, Springer, pp151, 2015.

Rootzén, H., Katz, R. W.: Design life level: quantifying risk in a changing climate, Water Resour. Res., 49(9), 5964-5972, 2013.

Rosbjerg, D., and Madsen, H.: Design with uncertain design values, Hydrology in a Changing Environment, Iii, 155-163, 1998.

Salas, J. D, and Obeysekera, J.: Revisiting the concepts of return period and risk for nonstationary hydrologic extreme events, J. Hydrol. Eng., 19(3), 554-568, 2013.

Salinas, J. L., Castellarin, A., Viglione, A., Kohnova, S., and Kjeldsen, T.: Regional parent flood frequency distributions in Europe-Part 1: Is the GEV model suitable as a pan-European parent?. Hydrol. Earth Syst. Sci., 18, 4381-4389, 2014.

30 Salvadori, G., Durante, F., and De Michele, C.: On the return period and design in a multivariate framework, Hydrol. Earth Syst. Sci., 15, 3293-3305, 2011.

Serinaldi, F., and Kilsby, C. G.: Stationarity is undead: Uncertainty dominates the distribution of extremes. Adv. Water Resour., 77, 17-36, 2015.

Stanberry, L.: Chi-Squared Test, Encyclopedia of Systems Biology, 399-400, 2013. 
Hydrol. Earth Syst. Sci. Discuss., doi:10.5194/hess-2016-566, 2017

Manuscript under review for journal Hydrol. Earth Syst. Sci.

Published: 7 February 2017

(c) Author(s) 2017. CC-BY 3.0 License.

(c) (i)
Hydrology and

Earth System

Sciences

Discussions

Su ,B. D., Kundzewicz, Z., and Jiang, T.: Simulation of extreme precipitation over the Yangtze River Basin using Wakeby distribution, Theor. Appl. Climatol., 96(3-4), 209-219, 2009.

Tian, Y., Xu, Y. P., Booij, M. J., and Wang, G.: Uncertainty in Future High Flows in Qiantang River Basin, China. J. Hydrometeorol., 16(1), 363-380, 2015.

5 Vetter, T., Huang, S., Aich, V., Yang, T., Wang, X., Krysanova, V., and Hattermann, F.: Multi-model climate impact assessment and intercomparison for three large-scale river basins on three continents, Earth System Dynamics, 6(1), 1743, 2015.

Vrugt, J. A., Ter Braak, C. J., Gupta, H. V., and Robinson, B. A.: Equifinality of formal (DREAM) and informal (GLUE) Bayesian approaches in hydrologic modeling?, Stoch. Env. Res. Risk A., 23(7), 1011-1026, 2009.

10 von Hippel, P. T.: Mean, median, and skew: Correcting a textbook rule. J.Stat. Education, 13(2), n2, 2005.

Von Storch, H., and Zwiers, F. W.: Statistical analysis in climate research. Cambridge university press, pp485, 2001.

Water Resources Council, USA.: Guidelines for determining flood flow frequency, Bulletin 17B, doi: http://dx.doi.org/10.3133/tm4-BXX/, 1982.

Westfall, P. H.: Kurtosis as peakedness, 1905-2014. RIP, Am. Stat., 68(3), 191-195, 2014.

15 Xu, Y. P., Booij, M. J., and Tong, Y. B.: Uncertainty analysis in statistical modeling of extreme hydrological events. Stoch. Env. Res. Risk A., 24(5), 567-578, 2010.

Yip, S., Ferro, C. A., Stephenson, D. B., and Hawkins, E.: A simple, coherent framework for partitioning uncertainty in climate predictions, J. Climate ,24(17), 4634-4643, 2011.

Zhu, Q., Xu, X., Gao, C., Ran, Q. H., and Xu, Y. P.: Qualitative and quantitative uncertainties in regional rainfall frequency analysis, J. Zhejiang Univ-SC A, 16(3), 194-203, 2015.

Zwiers, F.: A potential predictability study conducted with an atmospheric general circulation model, Mon. Weather Rev., 115(12), 2957-2974, 1987.

Zwiers, F. W.: Interannual variability and predictability in an ensemble of AMIP climate simulations conducted with the CCC GCM2, Clim. Dynam., 12(12), 825-847, 1996. 
Hydrol. Earth Syst. Sci. Discuss., doi:10.5194/hess-2016-566, 2017

Manuscript under review for journal Hydrol. Earth Syst. Sci.

Published: 7 February 2017

Table 1. Distribution functions fitted to hydrological samples from the Cuntan and Pingshan hydrological stations

\begin{tabular}{lll}
\hline Distribution Name & Probability Density Function & Cumulative Distribution Function
\end{tabular}

\begin{tabular}{lll}
\hline Gamma (Gam) & $f(x)=\frac{x^{\alpha-1}}{\beta^{\alpha} \Gamma(\alpha)} \exp \left(-\frac{x}{\beta}\right)$ & $F(x)=\frac{\Gamma_{x / \beta}(\alpha)}{\Gamma(\alpha)}$ \\
$\alpha, \beta(\alpha>0, \beta>0)$ & $F(x)=\exp (-\exp (-z))$ \\
Gumbel (Gum) & $f(x)=\frac{1}{\sigma} \exp (-z-\exp (-z))$ & \\
$\sigma, \mu(\sigma>0)$ &
\end{tabular}

Lognormal (LN)

$\sigma, \mu(\sigma>0)$

$$
f(x)=\frac{\exp \left(-\frac{1}{2}\left(\frac{\ln x-\mu}{\sigma}\right)^{2}\right)}{x \sigma \sqrt{2 \pi}}
$$

$$
F(x)=\Phi\left(\frac{\ln x-\mu}{\sigma}\right)
$$

\section{Pearson-III (P III)}

$\alpha, \beta, \gamma(\alpha>0, \beta>0)$

$$
f(x)=\frac{(x-\gamma)^{\alpha-1}}{\beta^{\alpha} \Gamma(\alpha)} \exp \left(-\frac{x-\gamma}{\beta}\right) \quad F(x)=\frac{\Gamma_{(x-\gamma) \beta}(\alpha)}{\Gamma(\alpha)}
$$

Generalized Extreme Value (GEV) $\quad f(x)=\left\{\begin{array}{c}\frac{1}{\sigma} \exp \left(-(1+k z)^{-1 / k}\right)(1+k z)^{-1-1 / k} \quad k \neq 0 \\ \frac{1}{\sigma} \exp (-z-\exp (-z)) \quad k=0\end{array} \quad F(x)=\left\{\begin{array}{cc}\exp \left(-(1+k z)^{-1 / k}\right) & k \neq 0 \\ \exp (-\exp (-z)) & k=0\end{array}\right.\right.$

Note: $z \equiv \frac{x-\mu}{\sigma} ; \Gamma(\alpha)=\int_{0}^{\infty} t^{\alpha-1} e^{t} d t \quad(\alpha>0) ; \Gamma_{x}(\alpha)=\int_{0}^{x} t^{\alpha-1} e^{-t} d t \quad(\alpha>0)$ 
Hydrol. Earth Syst. Sci. Discuss., doi:10.5194/hess-2016-566, 2017

Manuscript under review for journal Hydrol. Earth Syst. Sci.

Published: 7 February 2017

(c) Author(s) 2017. CC-BY 3.0 License.
Hydrology and

Earth System

Sciences

Discussions

(c) (i)

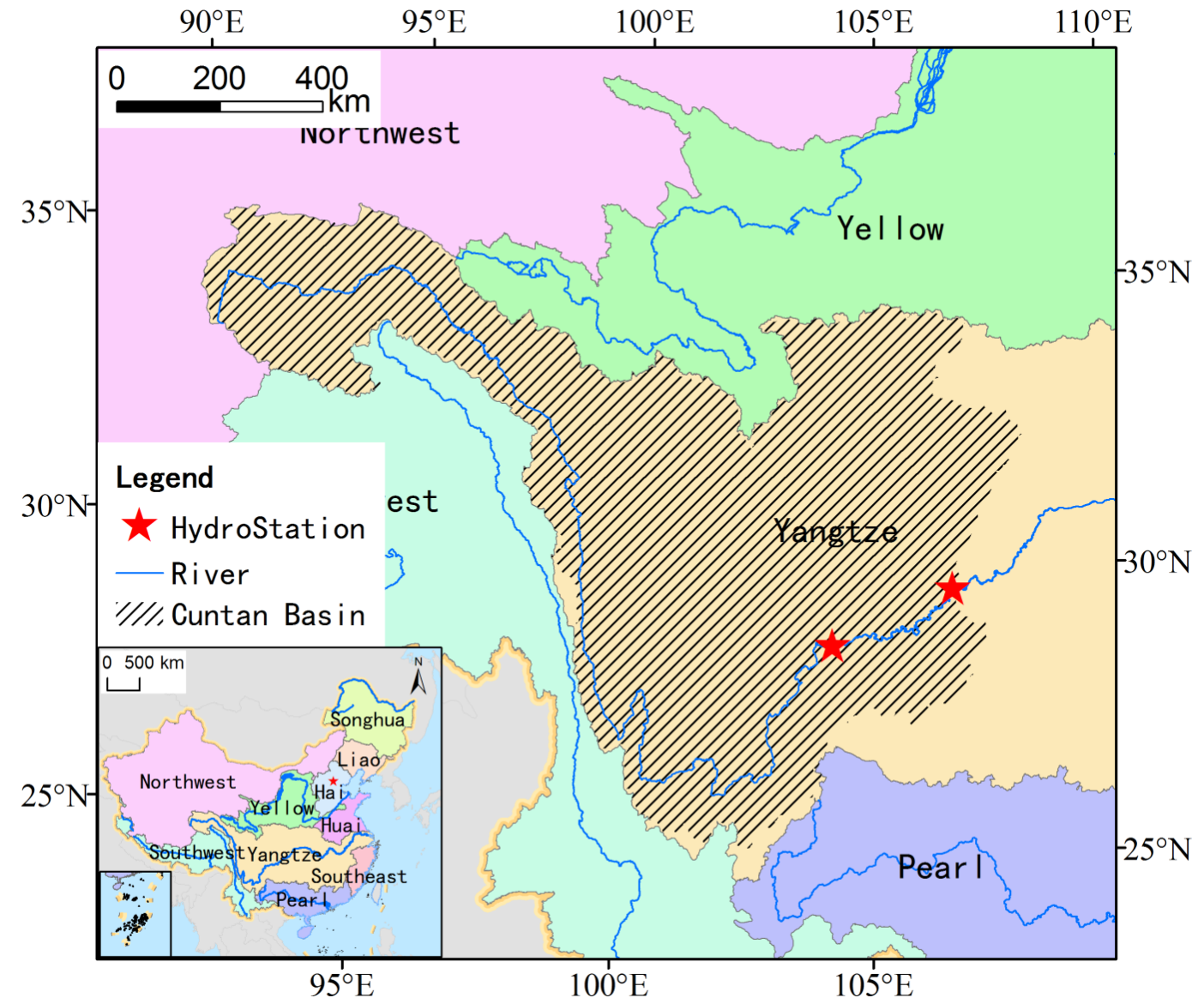

Figure 1: Locations of the hydrological stations in the Pingshan and Cuntan River basins on the upper Yangtze River, China. 
Hydrol. Earth Syst. Sci. Discuss., doi:10.5194/hess-2016-566, 2017

Manuscript under review for journal Hydrol. Earth Syst. Sci.

Published: 7 February 2017

(c) Author(s) 2017. CC-BY 3.0 License.

\section{(c) (1)}

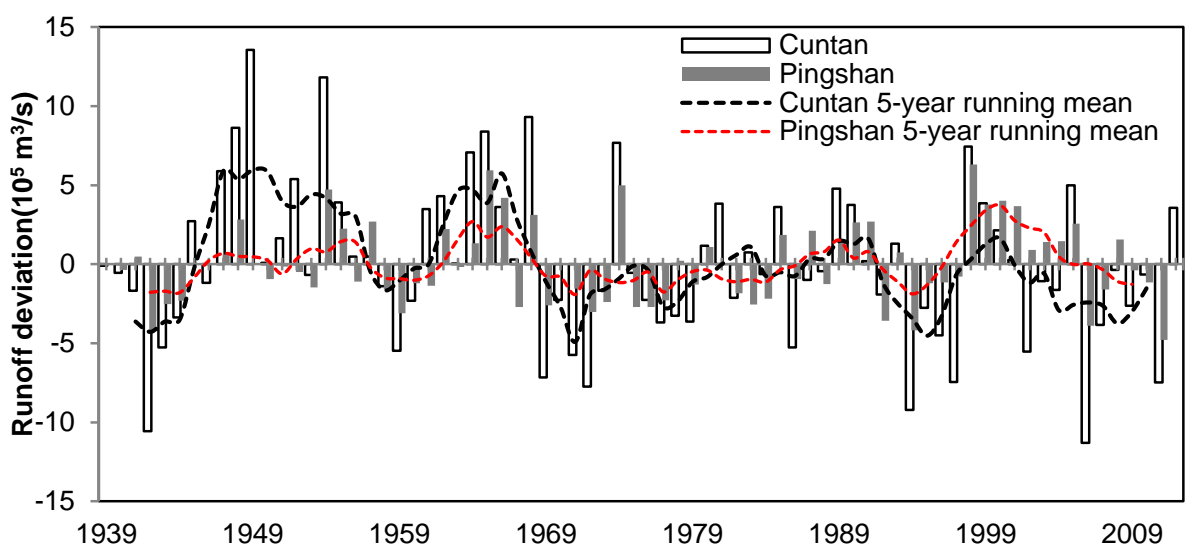

Hydrology and Earth System Sciences

Discussions

Figure 2: Annual total runoff at the Pingshan (gray histogram) and Cuntan (black histogram) hydrological stations. The black line represents the 5-year running mean at Cuntan. The red line represents the 5-year running mean at Pingshan. 
Hydrol. Earth Syst. Sci. Discuss., doi:10.5194/hess-2016-566, 2017

Manuscript under review for journal Hydrol. Earth Syst. Sci.

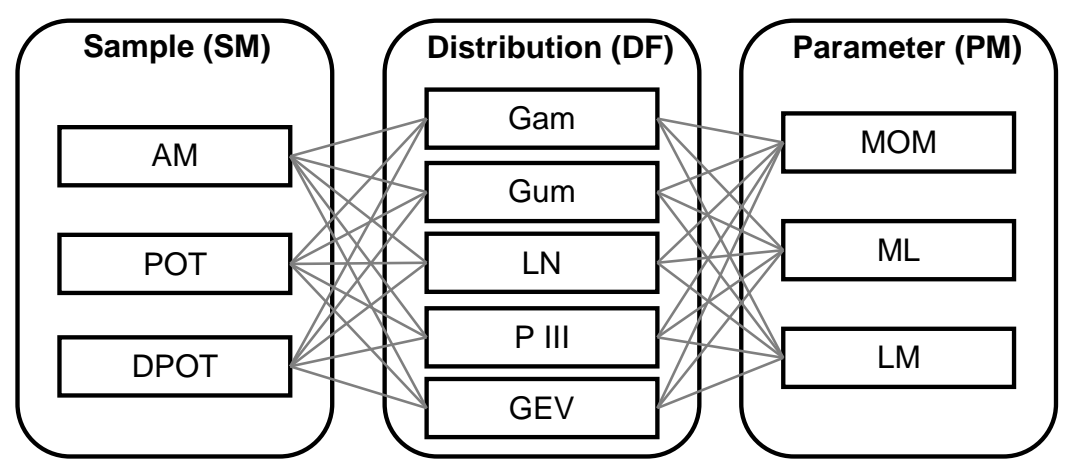

Figure 3: Modeling chain combination scheme. The three analyzed modeling chain elements are depicted from left to right. 
Hydrol. Earth Syst. Sci. Discuss., doi:10.5194/hess-2016-566, 2017

Manuscript under review for journal Hydrol. Earth Syst. Sci.

Published: 7 February 2017

(c) Author(s) 2017. CC-BY 3.0 License.
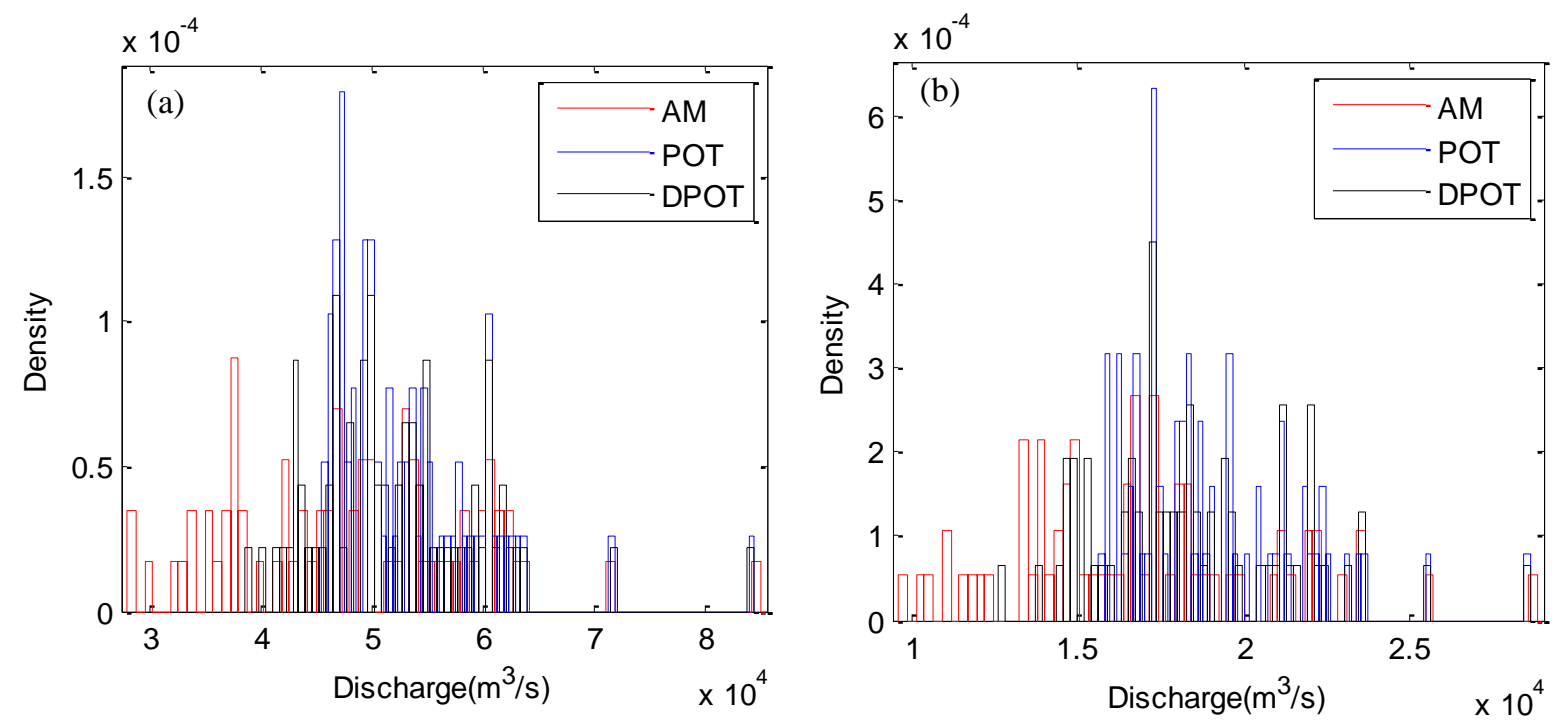

Figure 4: Three sample method frequency histogram for the extreme discharge series: (a) Cuntan and (b) Pingshan. Red, blue, and black histograms represent the AM, POT, and DPOT extreme discharge series, respectively. 
Hydrol. Earth Syst. Sci. Discuss., doi:10.5194/hess-2016-566, 2017

Manuscript under review for journal Hydrol. Earth Syst. Sci.

Published: 7 February 2017

(c) Author(s) 2017. CC-BY 3.0 License.
Hydrology and

Earth System

Sciences

Discussions
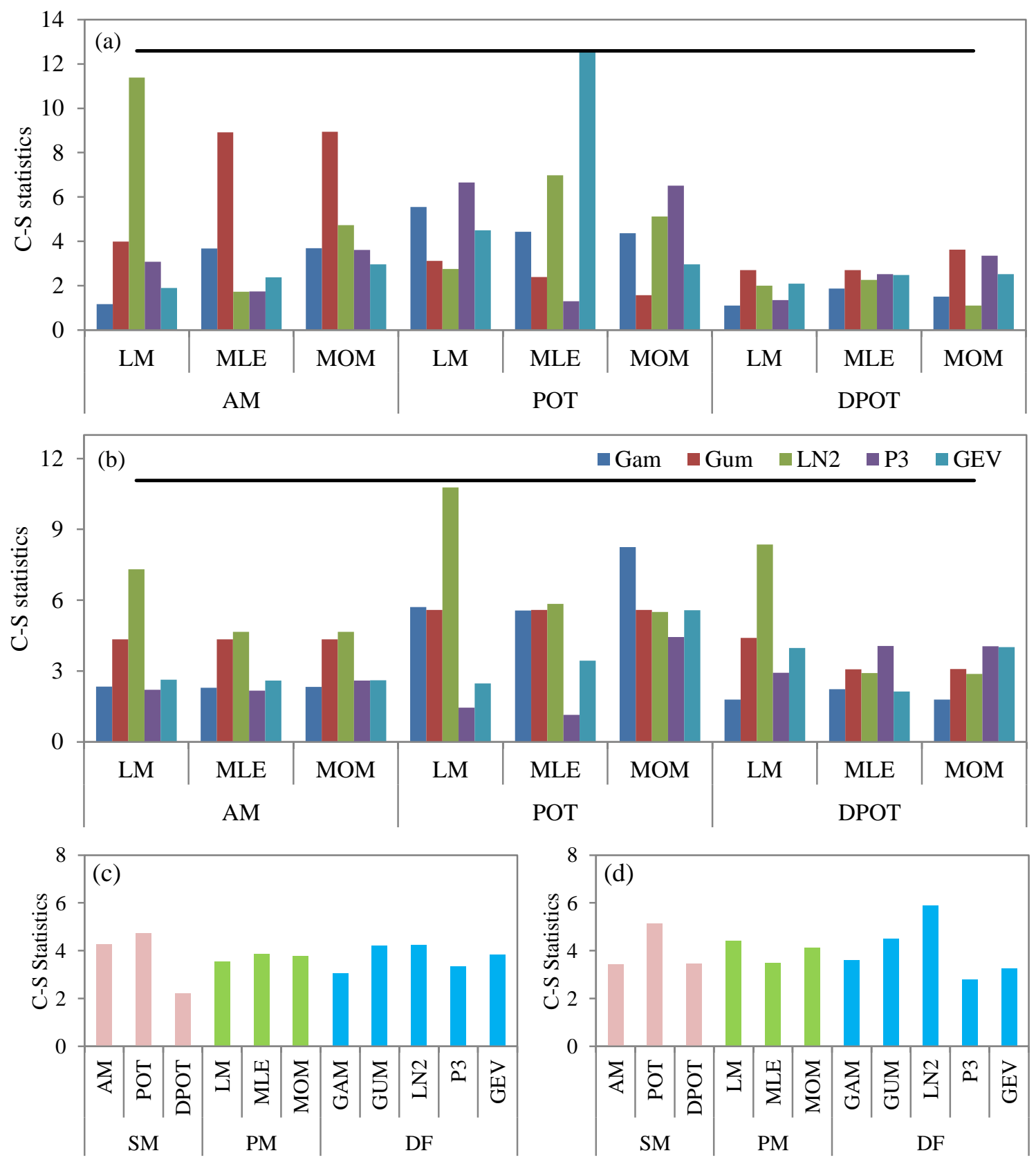

Figure 5: $\chi^{2}$ goodness of fit tests of different distributions: (a) and (c) Cuntan, and (b) and (d) Pingshan. Black line indicates the 50.05 significance level of $\chi^{2}$ goodness of fit tests. 
Hydrol. Earth Syst. Sci. Discuss., doi:10.5194/hess-2016-566, 2017

Manuscript under review for journal Hydrol. Earth Syst. Sci.

Published: 7 February 2017

(c) Author(s) 2017. CC-BY 3.0 License.

Hydrology and
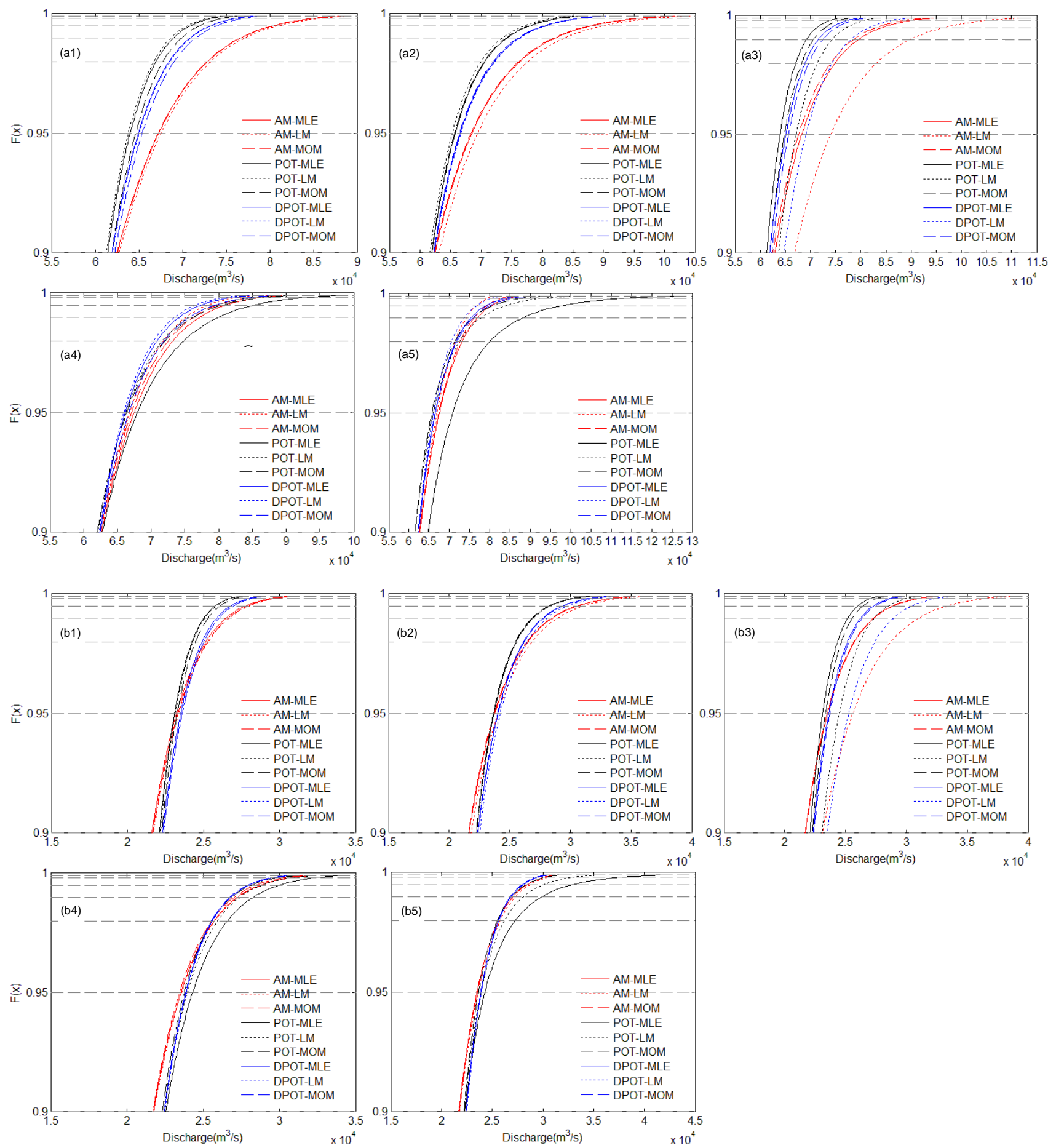

5 Figure 6: CDF of all combinations: (a) Cuntan and (b) Pingshan. 1-5 represent the CDFs of the GAM, GUM, LN, GEV, and P III DFs, respectively. 
Hydrol. Earth Syst. Sci. Discuss., doi:10.5194/hess-2016-566, 2017

Manuscript under review for journal Hydrol. Earth Syst. Sci.

Published: 7 February 2017

(c) Author(s) 2017. CC-BY 3.0 License.

\section{(c) (1)}
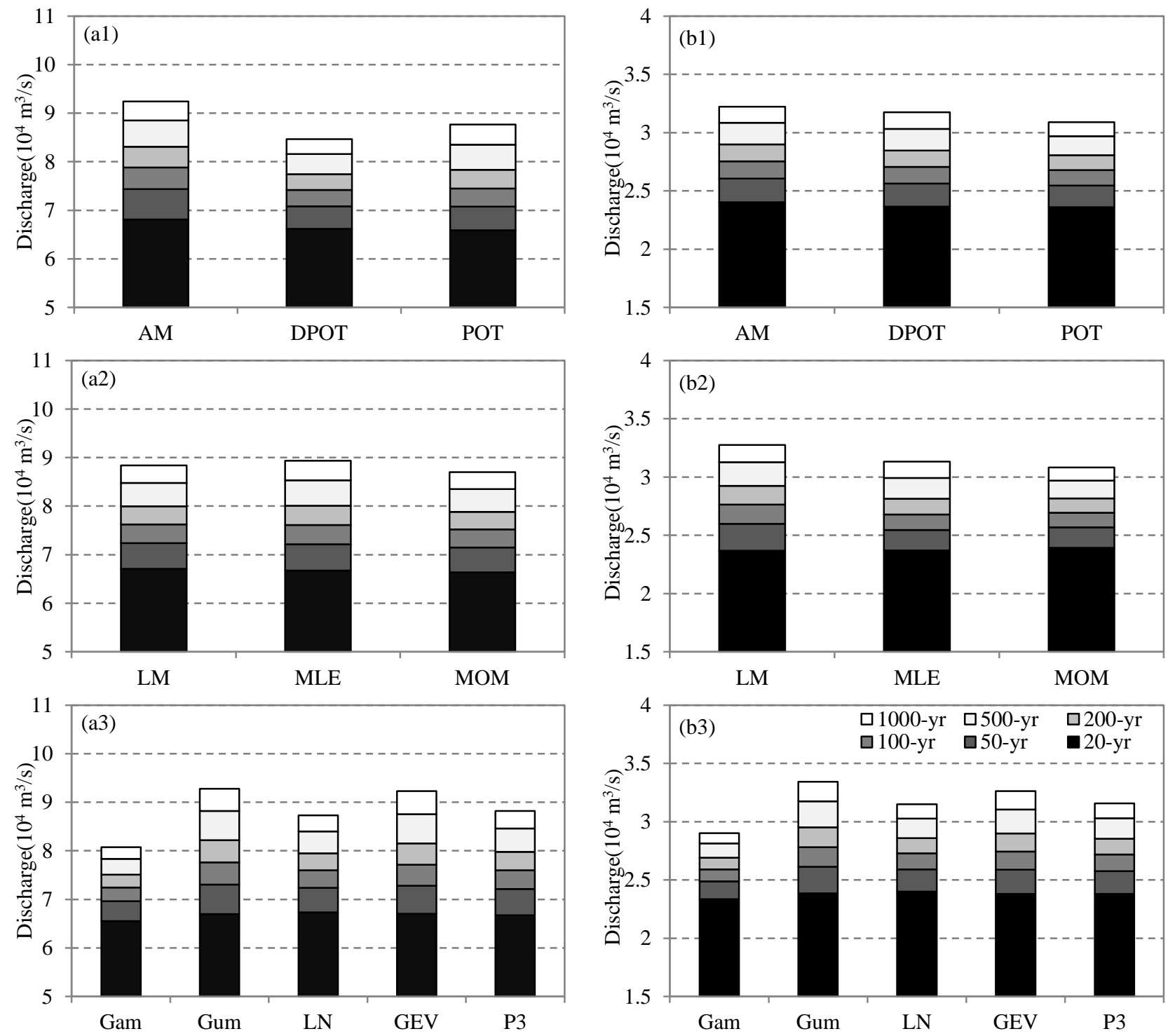

Figure 7: Average return levels to extreme discharge: (a) Cuntan and (b) Pingshan. 1-3 represent the average return levels

5 estimated by different SMs, PMs, and DFs. 
Hydrol. Earth Syst. Sci. Discuss., doi:10.5194/hess-2016-566, 2017

Manuscript under review for journal Hydrol. Earth Syst. Sci.

Published: 7 February 2017
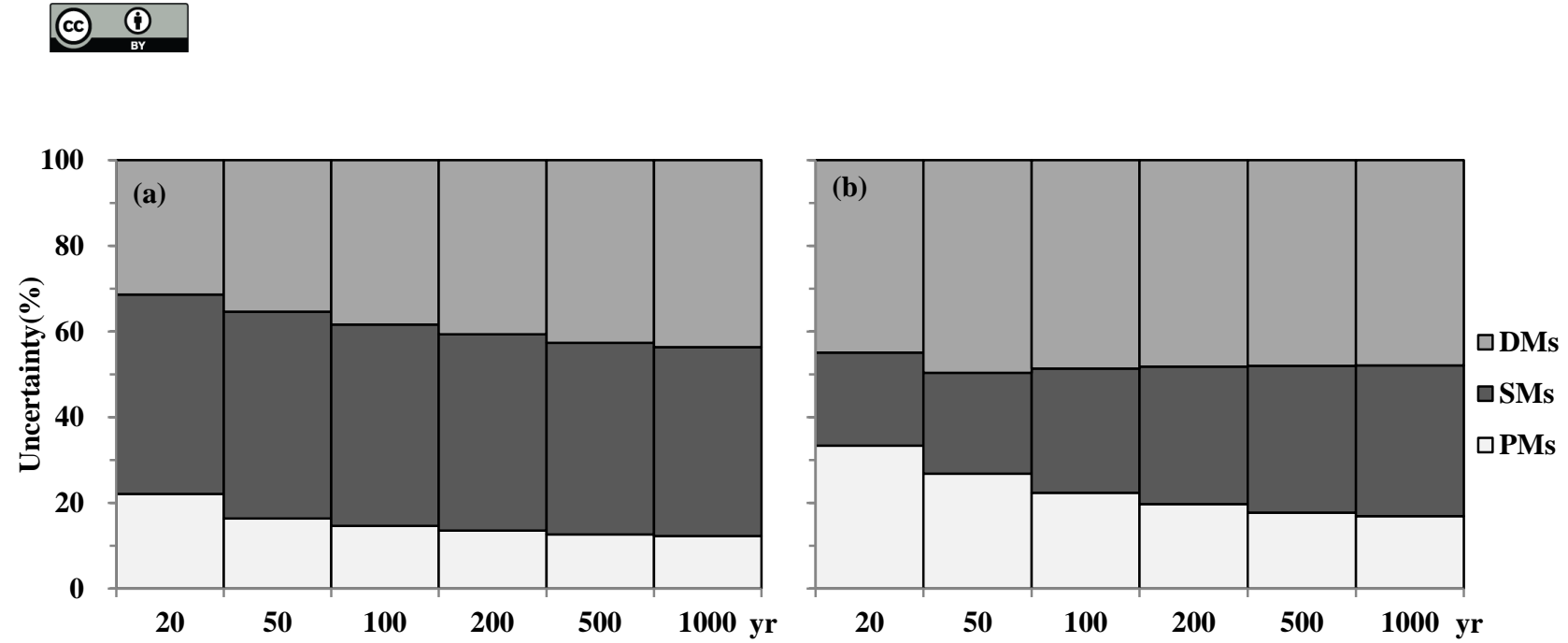

Figure 8: Contributions of different sources of uncertainty to overall uncertainty with subsampling scheme: (a) Cuntan and (b) Pingshan. 